\title{
A Instrumentalidade como uma Estratégia Motivacional
}

\author{
Adriana Rosecler Alcará \\ Sueli Édi Rufini Guimarães
}

No contexto educacional, a motivação dos alunos é um importante desafio a ser enfrentado, pois tem implicações diretas na qualidade do envolvimento do aluno com o processo de ensino e aprendizagem. $O$ aluno motivado busca novos conhecimentos e oportunidades, mostrando-se envolvido com o processo de aprendizagem, envolve-se nas tarefas com entusiasmo e demonstra disposição para novos desafios.

Estudos na área da motivação para a aprendizagem apontam como sendo um determinante motivacional as metas que os alunos assumem para 0 seu futuro. De acordo com seus proponentes, Lens, Simons e Dewitte (2002), a Perspectiva de Tempo Futuro diz respeito ao grau e ao modo pelo qual o futuro cronológico de uma pessoa é integrado ao espaço de vida presente. Segundo Kauffman e Husman (2004), as concepções de futuro dos alunos têm uma influência real e significativa sobre as suas crenças e sobre a sua motivação para aprender, o que, por conseguinte, influencia positivamente o seu desempenho.

Diretamente vinculada à motivação no presente está a percepção de instrumentalidade, ou seja, o aluno percebe que as atividades realizadas no presente consistem em meios para atingir as suas metas futuras. Tal percepção contribui para a valorização das atividades e, por conseguinte, promove o envolvimento e a aplicação de esforço.

A percepção de instrumentalidade foi objeto de estudo em diversas pesquisas realizadas com alunos universitários e os resultados forneceram um suporte empírico bastante rico sobre a idéia de que a percepção dos alunos da utilidade futura do que aprendem hoje pode ter efeitos positivos para a sua motivação. De modo geral, os alunos mais motivados conferem maior valor às metas futuras e percebem suas atividades como instrumentais para atingi-las. Ainda, os alunos que percebem a utilidade das atividades acadêmicas são mais entusiasmados e dedicam maior esforço para dominar todas as tarefas, comparados aos alunos que as vêem apenas como exercício ou treinamento.
Podemos perceber que a percepção de instrumentalidade configura-se em um recurso promissor, caso seja incluída nas estratégias motivacionais utilizadas pelos professores em ambientes de sala de aula. Vale ressaltar que, segundo Brophy (1999) as indicações para o uso de determinadas estratégias no contexto escolar, provenientes dos resultados de pesquisas empíricas, não são garantias seguras de envolvimento pleno por parte de todos os alunos. No entanto, há grande probabilidade de que o professor consiga atingir a maioria de seus alunos ou, quem sabe, todos eles, para um padrão ótimo de motivação.

Assim, considerando a eficácia de se aumentar nos alunos a percepção de instrumentalidade das tarefas escolares, especificamente no ensino superior, cabe ao professor articular as atividades do presente com a atuação profissional futura dos alunos, isto é, as atividades acadêmicas devem possibilitar ao aluno a visualização da possível utilidade do conteúdo estudado ou da habilidade desenvolvida hoje para o seu futuro profissional.

Outro aspecto a se considerar, diz respeito à percepção de instrumentalidade com regulação interna. Vale mencionar que, na regulação interna os motivos para o compromisso e envolvimento com determinada atividade estão dentro da própria pessoa. Essa combinação (percepção de instrumentalidade com regulação interna) pode ser exemplificada com aquele aluno que, além de perceber as atividades do presente como úteis para a sua atuação profissional futura, visualiza o valor destas para o seu crescimento pessoal. Assim, recai sobre o professor a responsabilidade de estimular nos alunos o planejamento e a adoção de metas futuras de maneira autônoma, possibilitando que estes as valorizem pessoalmente. Ainda, compete ao professor identificar os níveis reais de desenvolvimento ou conhecimento de seus alunos para propiciar em sala de aula desafios ótimos, nem demasiadamente altos ou baixos. Além disso, devem ser criadas oportunidades que despertem 0 interes- 
se dos alunos e os instiguem a fazer escolhas responsáveis e comprometidas com as conseqüências.

Contudo, apesar do seu grande valor como determinante motivacional, a Perspectiva de Tempo Futuro e a percepção de instrumentalidade não se configuram nas únicas variáveis que explicam as orientações motivacionais dos alunos. Há muitas que já foram descritas na literatura motivacional como, por exemplo, as crenças pessoais dos alunos acerca de sua competência; a percepção de autonomia diante das atividades solicitadas, neste caso $\circ$ aluno necessitaria acreditar que faz a atividade porque assim o quer e não por imposições externas; a percepção de vínculo ou de pertencer, isto é, de sentir-se valorizado naquela situação; as atribuições que os alunos fazem diante de fracassos, entre outras, amplamente pesquisadas e com importantes indicações para o trabalho em sala de aula.

Outras variáveis talvez ainda não tenham sido descritas ou explicadas pela pesquisa na área, o que torna $\circ$ problema de como motivar os alunos algo complexo. Isso merece uma atenção especial por parte dos professores e evidencia a necessidade do uso de diferentes estratégias para promover e manter a motivação no contexto acadêmico. Sobretudo, o professor deve buscar conhecer as diferentes abordagens teóricas da motivação e suas propostas de estratégias de intervenção, procurando utilizálas nas atividades acadêmicas. Além disso, é imprescindível a disposição do professor para refletir sobre as suas crenças e valores e, principalmente, sobre a sua ação pedagógica, buscando compreender e interpretar as ações dos seus alunos em sala de aula.
Vale ainda mencionar, que esta comunicação é um produto originado de uma pesquisa realizada com alunos universitários de uma instituição de ensino superior pública, que nos permitiu a visualização da intensidade e diversidade de fatores envolvidos na motivação acadêmica. Antes da realização deste estudo, tínhamos uma percepção bastante restrita dessa temática, principalmente, pelo desconhecimento das abordagens teóricas a respeito da motivação. Os conhecimentos adquiridos certamente proporcionarão uma mudança e incremento na atuação prática. Hoje, temos uma preocupação mais consciente em torno do uso de estratégias motivacionais, que focalizem o significado e o valor das atividades, bem como a valorização do esforço e do envolvimento do aluno. Assim, nossa atuação em sala de aula representa um grande desafio, com o compromisso de uma ação pedagógica mais reflexiva.

\section{Referências}

Brophy, J. (1999). Research on motivation in education: past, present and future. Em T. C. Urdan, M. Maehr, \& P. R. Pintrich (Ed.). Advances in motivation and achievement. (vol. I I, pp. I44). Greenwich: Jai Press.

Kauffman, D. F., \& Husman, J. (2004). Effects of time perspective on student motivation: introduction to a special issue. Educational Psychology Review, 16, (I), I-7.

Lens, W., Simons, J. \& Dewitte, S. (2002). The role of students's future time perspective and instrumentality percepctions for study motivation and self-regulation. Em F. Pajares, T. Urdan. Academic motivation of adolescents (cap. 8, pp. 221-245). Greenwich: IAP.

Sobre as autoras:

Adriana Rosecler Alcará (adrianaalcara@sercomtel.com.br) é Mestre em Educação e professora do curso de graduação em Biblioteconomia da Universidade Estadual de Londrina.

Sueli Édi Rufini Guimarães (sueli_rufini@hotmail.com) é Doutora em Educação pela Universidade Estadual de Campinas. Professora do Programa de Mestrado em Educação da Universidade Estadual de Londrina, na linha Docência: Saberes e Práticas e núcleo: Motivação no Contexto Escolar.

Endereço para correspondência:

Adriana Rosecler Alcará

Rua Almirante Crocane, I98 - Jd. Califórnia - 86040-100 - Londrina - PR

As autoras agradecem à CAPES pelo apoio financeiro com a manutenção da bolsa de auxílio 